\title{
Solving the dilemma of prevention of red cell alloimmunization
}

Evaluation of: Stephen J, Cairns LS, Pickford WJ, Vickers MA, Urbaniak SJ, Barker RN. Identification, immunomodulatory activity and immunogenicity of the major helper $\mathrm{T}$ cell epitope on the $\mathrm{K}$ blood group antigen. Blood 119(23), 5563-5574 (2012). Alloimmunization to blood group antigens is a major concern in transfusion medicine. This occurs when antigen-mismatched blood is transfused into a recipient lacking a red blood cell antigen that is expressed on the donor red blood cells. Alloimmunization in this case can result in future problems in finding compatible blood for transfusion and can cause hemolytic transfusion reactions. Alloimmunization can also occur in instances where a mother lacks a red blood cell antigen that is carried by the fetus. In these cases, alloimmunization can result in an antibody that can cross the placenta and cause moderate-to-severe problems in the fetus or newborn due to hemolytic anemia and/or inhibition of hematopoiesis. This is called hemolytic disease of the fetus and newborn. Stephen et al. describe a unique approach to producing a peptide tolerogen to prevent alloimmunization to a specific blood group antigen, K, in the Kell blood group system. They identify an immunodominant K peptide and use this peptide to show that it strongly stimulates human T-helper cells from K-immunized people in vitro and that it shows efficacy when used as a nasal tolerogen to suppress immunization with $\mathrm{K}$ protein in a mouse model. These results open the door for therapies aimed at the prevention and/or treatment of alloimmunization in both a transfusion setting and, importantly, in hemolytic disease of the fetus and newborn.

KEYWORDS: alloimmunization hemolytic disease of the fetus and newborn Kell tolerogenic peptide

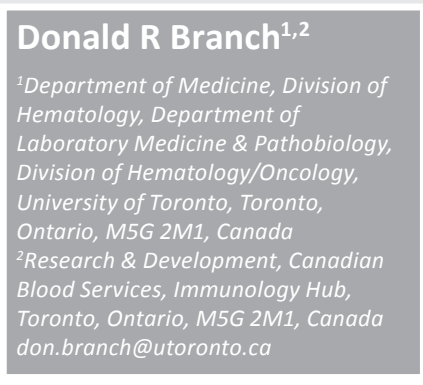
anti-D injection is given antenatally [3]. Since the introduction of RhIG prophylaxis, the incidence of HDFN due to anti-D has dramatically decreased. Unfortunately, this prophylactic therapy has not been shown to be successful for other blood group antigen mismatches. Indeed, another blood group antigen, $\mathrm{K}$, belonging to the Kell blood group system, has since moved to the forefront of important immunizations causing HDFN $[9,10]$. The effects of anti-K-mediated HDFN have been shown to be due both to hemolytic anemia and suppression of hematopoiesis $[11,12]$. To date, there are no immunebased prophylactic treatments for mothers at risk of immunization to fetal K-positive RBCs.

Stephen and colleagues have addressed the issue of prophylaxis in anti-K-mediated HDFN using an elegant approach [13]. These authors first screened $\mathrm{K}$ peptides against mononuclear cells from K-negative women who had produced anti-K to identify immunogenic $K$ peptides. A

\section{Future
Medicine $\mathrm{fS}$}


highly immunodominant peptide was identified that elicited strong immune tolerance for the production of anti-K in a mouse model. The authors conclude that their findings demonstrate the potential utility of such an approach to prevent immunization to $\mathrm{K}$ antigen in $\mathrm{K}$-negative mothers carrying K-positive babies.

\section{Summary of methods \& results}

The paper by Stephen et al. used 15 different synthetic peptide sequences containing 15 amino acids that covered the $\mathrm{K}$ protein from amino acids 179 to 207, which included a separate set of sequences for both the $\mathrm{K}$ allele and its single amino acid polymorphism that is the antithetical $\mathrm{k}$ blood group antigen at position 193 , either methionine $(\mathrm{K})$ or threonine $(\mathrm{k})$, respectively [13]. Additional control peptides consisted of the reverse sequences. An additional peptide was synthesized that was a glycosylated version of the $\mathrm{K}$ peptide. These peptides were used in stimulation assays of effector $\mathrm{T}$ cells as described previously by this group for $\mathrm{D}$ peptides [14], using proliferative response of peripheral blood mononuclear cells from ten women previously immunized to $\mathrm{K}$ and having produced anti-K compared with ten control women who were $\mathrm{K}$ negative but had no detectable anti-K. The most dominant stimulating peptide was WRISGKWTSLNFNRM, having the polymorphic residue at the C-terminus, which elicited a response in $90 \%$ of the donors. Of note, some responses were observed when using the k peptides and although these responses were not as strong as the responses to K peptides, they suggest some cross-reactivity or loss of tolerance of the $\mathrm{T}$ cells to other portions of the amino acid sequence surrounding this polymorphic amino acid. Indeed, the authors suggest that this site, which is normally glycosylated at amino acid 191 in the $\mathrm{k}$ but not the K protein, might be tolerogenic. Using a synthetic $\mathrm{k}$ peptide glycosylated at amino acid 191 showed no proliferative response supporting this notion. In addition, there were also some strong responses in the control, unimmunized cohort of donors suggesting perhaps that the assay used was not completely specific or that these K-negative donors were also immunized to the $\mathrm{K}$ antigen through undeclared transfusion/pregnancy or environmental exposure [15,16], which the authors offer as a possible explanation.

The authors go on to characterize the specific lymphocytes that proliferate in response to the peptide stimulation and identify using FACS analysis that the responding cell population consists of $\mathrm{CD}^{+}{ }^{+} \mathrm{CD}^{+}{ }^{+} \mathrm{T}$-helper cells of the memory phenotype as determined by expression of CD45RO. Using blocking antibodies to MHC class II, found almost exclusively on T-helper cells, confirmed the phenotype of the responding cell population.

To support the concept that the immunodominant $\mathrm{K}$ peptide may act as a tolerogen in vivo to prevent production of anti-K, the authors used a transgenic mouse model expressing human HLA-DR15 for processing the $\mathrm{K}$ peptide, previously used in tests of $\mathrm{D}$ antigen peptide-induced tolerance [17]. This model clearly showed that administration of the $\mathrm{K}$ peptide alone via the nasal mucosa prior to or following immunization with a K peptide-KLH-linked immunogen greatly suppressed the proliferative response of splenic $\mathrm{T}$ cells to the linked immunogen. This suppression was not seen using a control peptide or unlinked KLH, indicating that the suppression was specific to K.

\section{Discussion \& significance}

The success of identifying an immunodominant K peptide coupled with in vivo data that indicate this immunodominant peptide can provide tolerance to immunization with $\mathrm{K}$ protein is highly encouraging that this could lead to a means to prevent alloimmunization to K-positive RBCs. This opens up the possibility of provision of a prophylactic approach for prevention of HDFN in K-negative women. Currently, there is no means to prevent HDFN in these women, unlike women who are Rh-negative where RhIG prophylaxis has been provided successfully for many years. Importantly, as the in vivo immunosuppression was possible regardless of whether the immunization preceded or followed the administration of the tolerizing $\mathrm{K}$ peptide, this suggests that this approach might be applicable not only in HDFN but in cases of transfusion incompatibility to prevent alloimmunization to K-positive blood transfusions.

The approach used by these investigators is identical to that used previously to produce similar immunotolerant peptides of the $\mathrm{D}$ protein [14]; thus, this approach is probably applicable to other important blood group antigens that are clinically relevant, such as the $\mathrm{c}$ antigen of the Rh blood group system and the Kidd blood group antigens.

\section{Conclusion \& future perspective}

The current paper by Stephen et al. demonstrates the efficacy of using a synthetic peptide sequence to the $\mathrm{K}$ protein to induce tolerance to immunization by $\mathrm{K}$ protein. The work suggests 
that immunotherapy using blood group antigen peptides could be effective at providing suppression to immunization in the mother by fetal mismatched RBCs, preventing HDFN. Importantly, this work shows that this immunosuppression can be induced following immunization, thus supporting the idea that this immunotherapy may be able to reverse, or suppress, a fully established immune response to mismatched blood group antigens. Results in the mouse model are clearly encouraging, for both the $\mathrm{K}$ and $\mathrm{D}$ peptides [17]. However, despite the 2005 report [17] that used D antigen synthetic peptides as tolerogens, showing similar efficacy of suppression in the transgenic HLA-DR15 mouse model to D-positive antigen, there have been as yet no human studies to assess efficacy to prevent anti-D production. This current work is a very important contribution to transfusion medicine. However, translating this in vitro and mouse model work to humans can be a long process. Whether this approach to immunosuppression in humans will come to fruition is dependent on future studies in human volunteers whereby, for example, individuals who are $\mathrm{K}$ negative can be administered $\mathrm{K}$ peptide tolerogen or control peptide and then challenged with $\mathrm{K}$-positive RBCs and monitored for anti-K over time.

\section{Financial \& competing interests disclosure \\ The author has no relevant affiliations or financial involve- ment with any organization or entity with a financial inter- est in or financial conflict with the subject matter or materi- als discussed in the manuscript. This includes employment, consultancies, honoraria, stock ownership or options, expert testimony, grants or patents received or pending, or royalties. \\ No writing assistance was utilized in the production of this manuscript.}

\section{Executive summary}

- Peptides from $\mathrm{K}$ blood group protein can stimulate T cells from immunized women.

- Immunodominant K peptide stimulates T-helper cells.

- Immunodominant $\mathrm{K}$ peptide but not control peptide can suppress immunization to $\mathrm{K}$ protein in mice when administered nasally.

- The study suggests that immunodominant $K$ peptide may provide protection for hemolytic disease of the fetus and newborn and immunization to mismatched blood transfusions.

\section{References}

1 Daniels G, Poole J, deSilva M et al. The clinical significance of blood group antibodies. Transfus. Med. 12(5), 287-295 (2002).

2 Levine P, Pollack W. Hemolytic disease of the fetus and newborn. Med. Clin. North Am. 49(6), 1647-1660 (1965).

3 Kennedy MS. Perinatal issues in transfusion practice. In: Technical Manual (17th Edition). Roback JD (Ed.). American Association of Blood Banks, MD, USA, 631-643 (2008).

4 Duerbeck NB, Seeds JW. Rhesus immunization in pregnancy: a review. Obstet. Gynecol. Surv. 48(12), 801-810 (1993).

5 Gordon $\mathrm{H}$. The diagnosis of hydrops fetalis. Clin. Obstet. Gynecol. 14(2), 548-560 (1971).

6 Machin GA. Hydrops revisited: literature review of 1414 cases published in the 1980s. Am. J. Med. Genet. 34(3), 366-390 (1989).

7 Freda VJ, Gorman JG, Pollack W. Suppression of the primary $\mathrm{Rh}$ immune response with passive $\mathrm{Rh} \operatorname{IgG}$ immunoglobulin. N. Engl. J. Med. 277(19), 1022-1023 (1967).

8 Chown B, Bowman JM. Prevention of Rh immunization. Can. Med. Assoc. J. 100(6), 303-304 (1969).

9 Leggat HM, Gibson JM, Barron SL, Reid MM. Anti-Kell in pregnancy. Br. J. Obstet. Gynaecol. 98(2), 162-165 (1991).

10 Egbor M, Knott P, Bhide A. Red-cell and platelet alloimmunisation in pregnancy. Best Pract. Res. Clin. Obstet. Gynaecol. 26(1), 119-132 (2012).

11 Poole J, Daniels G. Blood group antibodies and their significance in transfusion medicine. Transfus. Med. Rev. 21(1), 58-71 (2007).

12 Vaughan JI, Manning M, Warwick RM, Letsky EA, Murray NA, Roberts IA. Inhibition of erythroid progenitor cells by anti-Kell antibodies in fetal alloimmune anemia. N. Engl. J. Med. 338(12), 798-803 (1998).
13 Stephen J, Cairns LS, Pickford WJ, Vickers MA, Urbaniak SJ, Barker RN. Identification, immunomodulatory activity and immunogenicity of the major helper $\mathrm{T}$ cell epitope on the K blood group antigen. Blood 119(23), 5563-5574 (2012).

14 Stott LM, Barker RN, Urbaniak SJ. Identification of alloreactive T-cell epitopes on the rhesus D protein. Blood 96(13), 4011-4019 (2000).

15 Marsh WL, Nichols ME, Oyen R et al. Naturally occurring anti-Kell stimulated by E. coli enterocolitis in a 20-day-old child. Transfusion 18(2), 149-154 (1978).

16 Hudson KE, Lin E, Hendrickson JE, Lukacher AE, Zimring JC. Regulation of primary alloantibody response through antecedent exposure to a microbial T-cell epitope. Blood 115(19), 3989-3996 (2010).

17 Hall AM, Cairns LS, Altmann DM, Barker RN, Urbaniak SJ. Immune responses and tolerance to the $\mathrm{RhD}$ blood group protein in HLA-transgenic mice. Blood 105(5), 2175-2179 (2005). 